\title{
Ankyloglossia and breastfeeding: what is the evidence of association between them?
}

Mariana do Rêgo Barros de Andrade Fraga ${ }^{1}$ https://orcid.org/0000-0001-8019-5984

Kamilla Azoubel Barreto 1

https://orcid.org/0000-0002-4691-5826

Thaís Christine Barbosa Lira ${ }^{1}$

https://orcid.org/0000-0003-1989-7076

Pâmella Robertha Rosselinne Paixão Celerino'

https://orcid.org/0000-0002-4607-6161

Izi Tuanny da Silva Tavares ${ }^{1}$ https://orcid.org/0000-0003-2300-8964

Valdenice Aparecida de Menezes ${ }^{1}$ https://orcid.org/0000-0003-4183-3239

Faculdade de Odontologia da Universidade de Pernambuco - FOP/ UPE, Recife, Pernambuco, Brasil.

Research support source: This study was financed, in part, by the Coordenação de Aperfeiçoamento de Pessoal de Nível Superior- Brasil (CAPES) - Finance Code 001

Conflict of interests: Nonexistent

\section{(c) (i)}

Received on: August 7, 2019

Accepted on: March 19, 2020

Corresponding address:

Mariana do Rêgo Barros de Andrade Fraga

Rua da Fundição, 377, apto 1601,

Santo Amaro

CEP: 50040-100 - Recife, Pernambuco,

Brasil

E-mail: marianaandrade.odonto@gmail. com

\section{ABSTRACT}

Purpose: to investigate the scientific evidence, in the literature, of the relationship between ankyloglossia and breastfeeding difficulties.

Methods: an integrative review of the literature. The MEDLINE and PubMed databases were searched, using the following descriptors in combination: "ankyloglossia", "newborn" and "breastfeeding". The searches included articles published between 2014 and 2019, in Portuguese, English and Spanish. Original articles demonstrating an association between ankyloglossia and breastfeeding issues were selected.

Results: a total of 31 articles was fully read in the analysis, 22 of which were excluded and 9 included in the review. There was a diversity of instruments used for the diagnosis of ankyloglossia. In four studies, no standardized evaluation instrument was used for the diagnosis of ankyloglossia, which may limit the analysis of the results. However, most studies have evidenced a possible influence of ankyloglossia on breastfeeding. According to the studies, babies with altered lingual frenulum were more likely to experience difficulties in sucking, showing early weaning, which shows the importance of neonatal screening as a routine protocol in maternity hospitals for the cases of ankyloglossia.

Conclusions: ankyloglossia may be related to impaired breastfeeding. The standardization of instruments for the diagnosis of ankyloglossia is necessary to improve the evidence in future research.

Keywords: Ankyloglossia; Newborn; Breastfeeding 


\section{INTRODUCTION}

Ankyloglossia is a congenital anomaly characterized by an abnormally short lingual frenulum or whose insertion is located near the tip of the tongue, thus limiting the tongue movements in terms of both protrusion and elevation ${ }^{1-3}$. The etiology of this alteration is still unknown. Some cases have a hereditary component, while others are not explained by genetics. It is characterized by the remaining residual tissue that did not suffer the expected apoptosis during embryonic development ${ }^{4}$.

The prevalence of ankyloglossia in newborns ranges from $0.52 \%$ to $21 \%$, being more frequent in males $^{5-18}$. Some authors consider such a prevalence to be underestimated, as cases of limited symptomatology are sometimes not diagnosed ${ }^{17}$.

Restricted tongue movement can have implications for oral hygiene, predisposing to dental caries, as well as speech disorders, and bullying in childhood and adolescence, with consequential social and developmental problems. Regarding the newborn, ankyloglossia is a controversial issue within and among medical specialties and multidisciplinary teams, when the nature of its interference in breastfeeding is discussed, as well as the most indicated treatment ${ }^{2,19-23}$.

The usual treatments for newborns with altered lingual frenulum include speech-language-hearing therapy and/or frenotomy. The surgical procedure is still discussed in the literature. There is no scientific evidence proving the procedure to be necessary to improve and prolong exclusive breastfeeding, concerning criteria such as the latch, and diminished nipple pain and crack $^{15,21,24-29}$.

In Brazil, considering the importance of breastfeeding for the newborn's growth and development and the possible interference of ankyloglossia in the breastfeeding process, the federal law no. 13,002 was proposed and approved in June 2014. It made the lingual frenulum evaluation protocol - also known in Portuguese as little tongue test - mandatory for babies, with the purpose of the multidisciplinary team's early diagnosing, treating and following up the cases ${ }^{9}$.

However, the obligatoriness of performing the test in all maternity hospitals in the country is still discussed by various professional categories, such as dental surgeons, physicians, and speech-language-hearing therapists. Those who oppose neonatal screening state that there is no difficulty to clinically diagnose the severe cases during the newborn's general evaluation; hence, they criticize the adoption of a standardized protocol for the screening because there is no gold standard protocol for the diagnosis of this alteration. The critical remarks also consider the absence of available evidence of an association between ankyloglossia and breastfeeding, and of the benefits of surgical treatment as a means of avoiding early weaning due to possible difficulties ${ }^{30,31}$.

Considering that neonatal lingual frenulum screening is a simple, painless, noninvasive, low-cost examination, which can be conducted by various trained professionals, and that ankyloglossia is more prevalent than other alterations diagnosed in a maternity hospital - such as the neonatal hearing screening (little ear test), which ranges from 0.1 to $0.6 \%$ of the newborns - the speech-language-hearing therapists defend that it be carried out as a means of early diagnosing and informing the parents about the presence of the alteration. Furthermore, it is important in offering guidance regarding the follow-up or treatment due to possible difficulties in breastfeeding, aiming to avoid early weaning and its consequences to the mother's and baby's general health ${ }^{32,33}$.

Thus, this paper aimed to investigate, in the literature, the scientific evidence of the relationship between ankyloglossia and breastfeeding difficulties.

\section{METHODS}

This article's method is an integrative literature review, whose intent is to gather and synthesize the scientific knowledge produced on the subject, making it possible to evaluate and summarize the evidence, contributing to its development. As it does not involve living beings, it was not necessary to have this paper approved by the Research Ethics Committee.

After the thematic issue had been established and its necessity confirmed, this review was conducted following these stages: development of the research question; search of the literature; data collection; critical analysis of studies included; discussion of the results; presentation and synthesis of the scientific evidence reviewed.

\section{Research question}

Does ankyloglossia influence breastfeeding?

\section{Search strategy}

The integrative literature review was conducted through an active search of information in the databases PubMed and MEDLINE. These databases were 
selected because they present high scientific credibility and a significant number of publications in the field being studied. Based on the research question, the descriptors that were likely to encompass the studies on the theme were defined; for that purpose, the Health Sciences Descriptors (DeCS) was consulted. The following descriptors were adopted: "ankyloglossia", "newborn" and "breastfeeding" (DeCS), combined by the Boolean operator AND.

The search and analysis process was conducted through independent paired evaluation. The combinations of keywords were entered into and the studies recorded in a spreadsheet. The duplicated studies and those that did not meet the inclusion criteria were excluded. For the selection of these articles, all the titles were read, followed by the full reading of all abstracts to verify whether they met the inclusion criteria. Then, the selected references were fully read. The information presented was organized according to the following criteria: authors, year of publication, country of origin of the research, age, population, objective, study design, and main outcomes. The publications were entered into the Mendeley software to manage the references. The last database query took place in May 2019.

\section{Article eligibility criteria}

Moreover, filters were used to facilitate the search, namely: original studies published from 2014 to 2019 (last five years), in either Portuguese, English or Spanish, available to be accessed. Studies related only to the quantitative demonstration of the prevalence of ankyloglossia and its etiology were excluded, as well as those that were focused exclusively on describing the technique for its treatment (e.g., frenotomy or frenectomy). Theses, dissertations, books, and other literature reviews were also excluded.

\section{Publication selection and data extraction}

The selected articles were independently analyzed by two researchers, who then compared their analyses to define its inclusion in the paper. When there were doubts about selecting a publication, a third researcher analyzed the articles to define whether to include it or not. When they disagreed, there was a discussion based on the inclusion criteria. The articles repeatedly indexed in both databases were considered only once. The publications were selected in two phases: (1) selection through reading the title and abstract; (2) qualitative analysis of the original articles in full. The flowchart with the detailed process of screening and selecting the articles is presented in Figure 1.

\section{LITERATURE REVIEW}

Through the previously established search criteria, nine articles that met the inclusion criteria were identified (Figure 2).

For the diagnosis of ankyloglossia, there was a diversity of instruments used in the selected studies. In four studies, no standardized evaluation instrument was used ${ }^{21,23,34,35}$, which characterize a limitation for the analysis of the results.

Although only a few studies have used standardized criteria to diagnose ankyloglossia ${ }^{10,14,19,20,36}$, it was noted that authors, in general, found some relationship between the alteration and breastfeeding difficulties ${ }^{14,19,20,21,23,34-36}$. In two studies conducted in Brazil, there was a relationship between breastfeeding difficulty complaints and the alteration in the frenulum. And, as observed in other studies ${ }^{22,35}$, the authors also concluded that the diagnosis of ankyloglossia is important and must be performed early, while in the maternity hospital ${ }^{19,20}$.

In this context, considering the responsibility of the health teams to encourage breastfeeding and early diagnose possible barriers to it through neonatal screenings, it was observed in a Canadian study that the ankyloglossia incidence rates increased from 6.86 per thousand live births in 2002 to 22.6 per thousand live births in 2014, which increased the frenotomy rates in the country associated with the desire to increase early breastfeeding rates ${ }^{13}$. The increase in ankyloglossia prevalence rates was also perceived in another study after an alteration diagnosis standard was adopted in the neonatal screenings ${ }^{10}$. These studies prove that many cases of ankyloglossia were being underreported and thus, untreated.

In Spain, a study with 667 newborns revealed ankyloglossia prevalence of $12.11 \%$, two to three times higher than the estimated (4\%). The authors used a standardized protocol to diagnose the alteration (Hazelbaker) and concluded that the diagnostic criteria must be unified ${ }^{10}$. This result was similar to the one found in another study conducted in Thailand (13.4\%) with 833 newborns, which also conducted neonatal screening and used standardized diagnosis protocol (Kotlow test) $^{36}$.

Hence, adopting a standardized protocol is indispensable for diagnosing the alteration and for early carrying out the treatment. It is also important for 


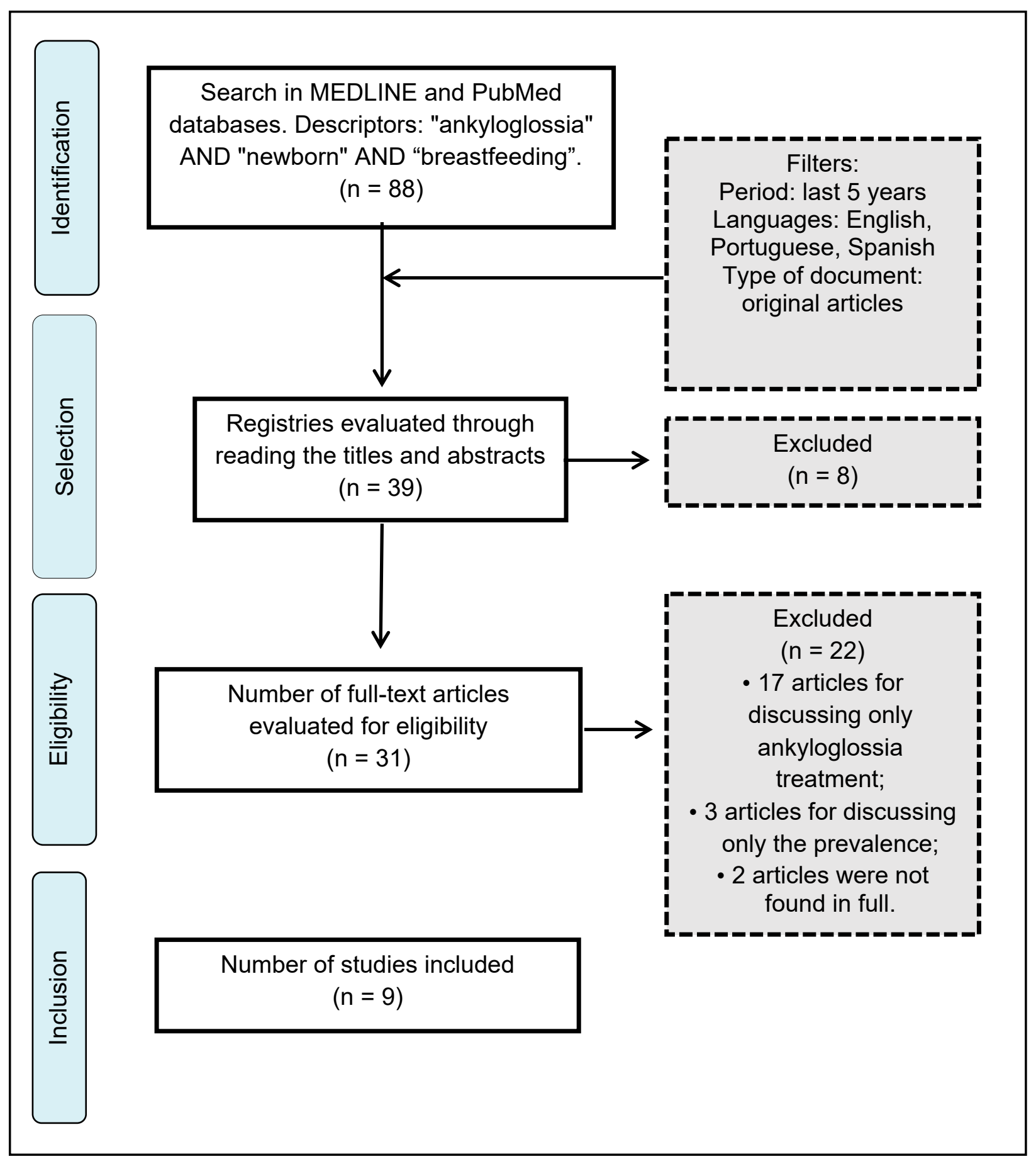

Figure 1. Flowchart of the article search and selection strategy in the MEDLINE and PubMed databases

obtaining better scientific evidence through more trustworthy results. However, there is not yet a universal acceptance of which protocol to use.

In this review, it was noted that, of the five studies that made the diagnosis through standardized instruments, in three the authors concluded that there was a relationship between ankyloglossia and breastfeeding difficulties ${ }^{19,20,36}$. In another study conducted in Spain with 302 newborns, the authors also used standardized instruments to diagnose the lingual frenulum and found a high prevalence of ankyloglossia (56.6\%) in the group of patients with breastfeeding problems. They concluded that this alteration, associated with breastfeeding problems, must be treated by a multidisciplinary team ${ }^{14}$.

Studies make evident that in the presence of the alteration associated with breastfeeding difficulties, two categories of signs and symptoms can arise: those 


\begin{tabular}{|c|c|c|c|c|c|}
\hline Author/Year & Country & TypeofStudy & Sample & $\begin{array}{l}\text { Instrument used } \\
\text { to diagnose } \\
\text { ankyloglossia }\end{array}$ & Results \\
\hline $\begin{array}{l}\text { Campanha, } \\
\text { Martinelli, Palhares, } \\
2019\end{array}$ & Brazil & $\begin{array}{l}\text { Cross-sectional } \\
\text { study }\end{array}$ & 130 & $\begin{array}{c}\text { LFEPI } \\
\text { "Little Tongue Test" }\end{array}$ & $\begin{array}{l}\text { There is an associationbetween } \\
\text { breastfeeding difficulty complaint } \\
\text { and ankyloglossia }\end{array}$ \\
\hline Walker et al., 2018 & USA & $\begin{array}{c}\text { Prospective cohort } \\
\text { study }\end{array}$ & 100 & $\begin{array}{l}\text { No standardized } \\
\text { instrument was } \\
\text { used to diagnose } \\
\text { ankyloglossia }\end{array}$ & $\begin{array}{c}\text { There was a relationship between } \\
\text { the short frenulumand maternal } \\
\text { nipple painwhile breastfeeding }\end{array}$ \\
\hline $\begin{array}{l}\text { Férres-Amat et al., } \\
2017\end{array}$ & Spain & $\begin{array}{l}\text { Cross-sectional } \\
\text { study }\end{array}$ & 302 & Coryllos & $\begin{array}{l}\text { High prevalence of ankyloglossia } \\
\text { in the group of patientswith } \\
\text { breastfeeding difficulties }\end{array}$ \\
\hline Araújo et al., 2019 & Brazil & $\begin{array}{l}\text { Cross-sectional } \\
\text { study }\end{array}$ & 449 & BTAT and LFEPI & $\begin{array}{l}\text { Alterations in the frenulumare } \\
\text { associated with interferences in } \\
\text { the quality of breastfeeding }\end{array}$ \\
\hline $\begin{array}{l}\text { Billington, Yardley, } \\
\text { Upadhyaya, } 2018\end{array}$ & England & Prospective study & 100 & $\begin{array}{l}\text { No standardized } \\
\text { instrument was } \\
\text { used to diagnose } \\
\text { ankyloglossia }\end{array}$ & $\begin{array}{c}\text { Ankyloglossia in infants is } \\
\text { considered a significant } \\
\text { cause of difficultiesto } \\
\text { maintainbreastfeeding }\end{array}$ \\
\hline $\begin{array}{l}\text { Pransky, Lago, Hong, } \\
2015\end{array}$ & USA & $\begin{array}{l}\text { Retrospective } \\
\text { study }\end{array}$ & 618 & $\begin{array}{l}\text { No standardized } \\
\text { instrument was } \\
\text { used to diagnose } \\
\text { ankyloglossia } \\
\end{array}$ & $\begin{array}{l}\text { Ankyloglossia can contributeto } \\
\text { breastfeeding difficulties }\end{array}$ \\
\hline Riskin et al., 2014 & Israel & $\begin{array}{l}\text { Observational } \\
\text { study }\end{array}$ & 183 & $\begin{array}{l}\text { No standardized } \\
\text { instrument was } \\
\text { used to diagnose } \\
\text { ankyloglossia }\end{array}$ & $\begin{array}{l}\text { The mothers of infants with } \\
\text { ankyloglossia reported } \\
\text { significantly more problems with } \\
\text { latch, prolonged breastfeeding, } \\
\text { andchild's fatigue while } \\
\text { breastfeeding }\end{array}$ \\
\hline $\begin{array}{l}\text { González-Jiménez } \\
\text { et al., } 2014\end{array}$ & Spain & $\begin{array}{l}\text { Cross-sectional } \\
\text { study }\end{array}$ & 667 & $\begin{array}{l}\text { Coryllos and } \\
\text { Hazelbaker }\end{array}$ & $\begin{array}{c}\text { More studies are necessaryto } \\
\text { determinethe association between } \\
\text { ankyloglossia and breastfeeding } \\
\text { difficulties, as well as other health } \\
\text { problems }\end{array}$ \\
\hline $\begin{array}{l}\text { Puopornpong et al., } \\
2014\end{array}$ & Thailand & $\begin{array}{l}\text { Cross-sectional } \\
\text { study }\end{array}$ & 833 & Kotlow test & $\begin{array}{c}\text { Latch scores were } \\
\text { significantlylower in } \\
\text { newbornswith ankyloglossia } \\
\text { in comparisonwiththe normal } \\
\text { newborns }\end{array}$ \\
\hline
\end{tabular}

Legend: LFEPI = lingual frenulum evaluation protocol for infants; BTAT =Bristol tongue-tie assessment tool

Figure 2. Studies selectedfor the review

related to nipple trauma and those related to ineffective breastfeeding and the child's consequent low nutritional intake ${ }^{19,22}$.

In a prospective cohort study conducted with 100 mothers/babies, there was an association between length from the tip of the tongue to the lingual frenulum insertion and the mother's nipple pain. The authors concluded that the less the distance higher are the scores of nipple pain ${ }^{34}$. However, an observational study conducted with 183 mothers/babies with ankyloglossia, who were compared with a control group of mother/babies without ankyloglossia, analyzed the clinical implications of ankyloglossia from the mothers' standpoint. It was observed that, despite their reporting difficulties related to latch, prolonged breastfeeding, and the newborn's fatigue when breastfeeding, no differences were noted regarding nipple pain, and the breastfeeding rates in the sixth month were similar in both groups ${ }^{35}$. 
On the other hand, in another longitudinal follow-up study conducted with 100 mothers/babies, the authors concluded that ankyloglossia in newborns can be considered a significant cause of difficulties in maintaining breastfeeding ${ }^{21}$. Nevertheless, this result must be cautiously analyzed, since the diagnosis of ankyloglossia was conducted only through clinical examination, without using standardized instruments.

Despite the various studies listing different aspects concerning factors that would lead to difficulties of newborns with ankyloglossia to breastfeed, all unbalance that can impair the sucking process and consequently, breastfeeding - due to nipple pain, nipple crack, incorrect latch, inadequate movement of perioral musculature, frequent hiccups and chokes after breastfeeding, excessive fatigue when breastfeeding, irritability when breastfeeding, or low weight gain - must be considered possible causes of weaning. Therefore, they must be early diagnosed and treated.

In this sense, it was noted in some studies that the frenotomy performed in the newborn's first days of life contributed to improved breastfeeding, which suggests a strong relationship between the breastfeeding difficulties and ankyloglossia ${ }^{25,26,28,29,37-39}$.A study conducted in England with 100 newborns with ankyloglossia and difficulties to breastfeed showed that frenotomy completely solved the breastfeeding complaints in $80 \%$ of the cases three months after the surgery. The authors concluded that the children early submitted to frenotomy managed to maintain exclusive breastfeeding for longer when compared to the national data on breastfeeding rates ${ }^{21}$.

Nonetheless, despite the selected studies suggesting a strong relationship between ankyloglossia and the difficulties at the beginning of breastfeeding, only one of them evidenced such an association ${ }^{19}$; and only one prospective study associated ankyloglossia with prolonged breastfeeding, though the authors did not use any standardized instrument to diagnose ankyloglossia ${ }^{21}$.

Most of the studies presented in this review resulting from the search in the databases with high scientific credibility and a significant number of publications in the field being studied - are cross-sectional, and the few prospective studies present reduced convenience sample. Furthermore, the breastfeeding problems related to ankyloglossia are surrogate endpoints (e.g., difficulty to breastfeed, nipple pain, quality of breastfeeding, latch problems, child's fatigue). No study, though, presented an association with clinical outcomes, as the child's weight loss or early interruption of exclusive breastfeeding.

Thus, it has become evident that conducting more clinical studies using standardized protocols to diagnose ankyloglossia is needed, to clarify the association between this alteration and difficulties at the beginning of breastfeeding. Moreover, longitudinal studies are necessary to evaluate prolonged breastfeeding and early weaning in newborns concerning lingual frenulum alteration.

\section{FINAL CONSIDERATIONS}

This review pointed out that, although the association between ankyloglossia and breastfeeding difficulties need more clinical studies to be evidenced, the selected studies suggest that the newborns with altered lingual frenulum are more likely to present difficulties in sucking, showing early weaning.

The early diagnosis proved to be of great importance to the cases of ankyloglossia, since it provides their follow-up and/or treatment, diminishing the probability of early weaning, which in turn avoids the consequences to the mother's and baby's general health.

Hence, it is important that neonatal screening be instituted as a routine protocol in maternity hospitals. Moreover, the instruments to diagnose ankyloglossia must be standardized so as to improve its scientific evidence in future research.

\section{REFERENCES}

1. Ito $Y$. Does frenotomy improve breastfeeding difficulties in infants with ankyloglossia? Pediatr Int. 2014;56(4):497-505.

2. Yousefi J, Tabrizian Namini F, Raisolsadat SM, Gillies R, Ashkezari A, Meara JG. Tongue-tie repair: Z-Plasty Vs Simple Release. Iran J Otorhinolaryngol. 2015;27(79):127-35.

3. Canadian Agency for Drugs and Technologies in Health. Frenectomy for the Correction of Ankyloglossia: a review of clinical effectiveness and guidelines [Internet]. [Útimo acesso: Jun 2019]. Disponível em: https://www.ncbi.nlm.nih.gov/ pubmed/27403491.

4. Knox I. Tongue-tie and frenotomy in the breastfeeding newborn. Neo Reviews. 2010;11(9):513-9.

5. Messner A, Lalakea LM. The effect of ankyloglossia on speech in children. Otolaryngol. Head Neck Surg. 2002;127(6):539-45. 
6. Hogan M, Westcott C, Griffiths M. Randomized, controlled trial of division of tongue-tie in infants with feeding problems. J Paediatr Child Health. 2005;41(5-6):246-50.

7. Ricke LA, Baker NJ, Madlon-Kay DJ, Defor TA. Newborn tongue-tie: prevalence and effect on breast-feeding. J Am Board Fam Pract. 2005;18(1):1-7.

8. Segal LM, Stephenson R, Dawes M, Feldman $P$. Prevalence, diagnosis, and treatment of ankyloglossia: methodologic review. Can Fam Physician. 2007;53(6):1027-33.

9. Martinelli RLC, Marchesan IQ, Berretin-Felix G. Protocol for infants: relationship between anatomic and functional aspects. Rev. CEFAC. 2013;15(3):599-609.

10. González JD, Costa RM, Riaño GI, González MMT, Rodríguez PMC, Lobete PC. Prevalence of ankyloglossia in newborns in Asturias (Spain). An Pediatr. 2014;81(2):115-9.

11. Francis DO, Krishnaswami S, McPheeters $M$. Treatment of ankyloglossia and breastfeeding outcomes: a systematic review. Pediatrics. 2015;135(6):1458-66.

12. Walsh J, Tunkel D. Diagnosis and treatment of ankyloglossia in newborns and infants: a review. JAMA Otolaryngol Head Neck Surg. 2017;143(10):1032-9.

13. Lisonek M, Liu S, Dzakpasu S, Moore AM, Joseph KS. Changes in the incidence and surgical treatment of ankyloglossia in Canada. Paediatr Child Health. 2017;22(7):382-6.

14. Ferrés-Amat $E$, Pastor-Vera $T$, Rodriguez-Alessi $P$, Ferrés-Amat E, Mareque-Bueno J, Ferrés-Padró $\mathrm{E}$. The prevalence of ankyloglossia in 302 newborns with breastfeeding problems and sucking difficulties in Barcelona: a descriptive study. Eur J Paediatr Dent. 2017;18(4):319-25.

15. Kumar RK, Prabha PCN, Kumar P, Patterson $\mathrm{R}$, Nagar N. Ankyloglossia in infancy: an Indian experience. Indian Pediatr. 2017;54(2):125-7.

16. Power R, Murphy J. Tongue-tie and frenotomy in infants with breastfeeding difficulties: achieving a balance. Arch Dis Child. 2015;100(5):489-94.

17. Veyssiere A, Kun-Darbois JD, Paulus C, Chatellier A, Caillot $A$, Bénateau $H$. Diagnosis and management of ankyloglossia in young children. Rev Stomatol Chir Maxillofac Chir Orale. 2015;116(4):215-20.

18. Fujinaga Cl, Chaves JC, Karkow IK, Klossowski DG, Silva FR, Rodrigues AH. Lingual frenum and breast feeding: descriptive study. Audiol Commun Res. 2017;22(e1762):1-7.

19. Campanha SMA, Martinelli RLC, Palhares DB. Association between ankyloglossia and breastfeeding. CODAS. 2019;31(1):e20170264.

20. Araujo MDCM, Freitas RL, Lima MGS, Kozmhinsky VMDR, Guerra CA, Lima GMS et al. Evaluation of the lingual frenulum in newborns using two protocols and its association with breastfeeding. $J$ Pediatr. 2019 Apr 25. pii: S0021-7557(18)30836-2. doi: 10.1016/j.jped.2018.12.013.

21. Billington J, Yardley I, Upadhyaya M. Long-term efficacy of a tongue tie service in improving breastfeeding rates: a prospective study. J Pediatr Surg. 2018; 53(2):286-8.

22. Manipon C. Ankyloglossia and the breastfeeding infant: assessment and intervention. Adv Neonatal Care. 2016;16(2):108-13.

23. Pransky SM, Lago D, Hong P. Breastfeeding difficulties and oral cavity anomalies: the influence of posterior ankyloglossia and upper-lip ties. Int $\mathrm{J}$ Pediatr Otorhinolaryngol. 2015;79(10):1714-7.

24. Suter VG, Bornstein MM. Ankyloglossia: facts and myths in diagnosis and treatment. J Periodontol. 2009;80(8):1204-19.

25. Muldoon K, Gallagher L, McGuinness D, Smith V. Effect of frenotomy on breastfeeding variables in infants with ankyloglossia (tongue-tie): a prospective before and after cohort study. BMC Pregnancy Childbirth. 2017;17(1):373.

26. O'Shea JE, Foster JP, O'Donnell CP, Breathnach D, Jacobs SE, Todd DA et al. Frenotomy for tongue-tie in newborn infants. Cochrane Database Syst Rev. 2017 Mar 11;3:CD011065. doi: 10.1002/14651858. CD011065.pub2.

27. Patel J, Anthonappa RP, King NM. All tied up! Influences of oral frenulae on breastfeeding and their recommended management strategies. J Clin Pediatr Dent. 2018;42(6):407-13.

28. Srinivasan A, Al Khoury A, Puzhko S, Dobrich $\mathrm{C}$, Stern $\mathrm{M}$, Mitnick $\mathrm{H}$ et al. Frenotomy in infants with tongue-tie and breastfeeding problems. J Hum Lact. 2018 Dec 13:890334418816973. doi: $10.1177 / 0890334418816973$.

29. Brzęcka D, Garbacz M, Micał M, Zych B, Lewandowski B. Diagnosis, classification and management of ankyloglossia including its influence on breastfeeding. Dev Period Med. 2019;23(1):79-87. 
30. Associação Brasileira de Odontopediatria. [Internet]. [Último acesso em junho de 2019]. Disponível em: https://abodontopediatria.org.br/ site $/ ? p=785$.

31. Sociedade Brasileira de Pediatria. [Internet]. [Último acesso em junho de 2019]. Disponível em: https://www.sbp.com.br/imprensa/detalhe/nid/ sbp-solicita-ao-ministerio-da-saude-revogacao-dalei-que-torna-obrigatorio-o-teste-da-linguinha-emrecem-nascidos/.

32. Brasil. Ministério da Saúde. Secretaria de Atenção à Saúde. Departamento de Ações Programáticas Estratégicas. Diretrizes de Atenção da Triagem Auditiva Neonatal / Ministério da Saúde, Secretaria de Atenção à Saúde, Departamento de Ações Programáticas Estratégicas e Departamento de Atenção Especializada. - Brasília: Ministério da Saúde, 2012.

33. Conselho Regional de Fonoaudiologia 4a região. [Internet]. [Último acesso em: junho de 2019]. Disponível em: http://www.crefono4.org.br/noticias/ noticia/1419/nota-de-repudio.

34. Walker RD, Messing S, Rosen-Carole C, McKenna Benoit M. Defining tip-frenulum length for ankyloglossia and its impact on breastfeeding: a prospective cohort study. Breastfeed Med. 2018;13(3):204-10.

35. Riskin A, Mansovsky M, Coler-Botzer T, Kugelman A, Shaoul R, Hemo Met al. Tongue-tie and breastfeeding in newborns-mothers' perspective. Breastfeed Med. 2014;9(9):430-7.

36. Puapornpong $\mathrm{P}, \quad$ Raungrongmorakot K, Mahasitthiwat V, Ketsuwan S. Comparisons of the latching on between newborns with tongue-tie and normal newborns. J Med Assoc Thai. 2014;97(3):255-9.

37. Wong K, Patel P, Cohen MB, Levi JR. Breastfeeding infants with ankyloglossia: insight into mothers' experiences. Breastfeed Med. 2017;12(2):86-90.

38. Ghaheri BA, Cole M, Fausel SC, Chuop M, Mace JC. Breastfeeding improvement following tongue-tie and lip-tie release: a prospective cohort study. Laryngoscope. 2017;127(5):1217-23.

39. Wakhanrittee J, Khorana J, Kiatipunsodsai S. The outcomes of a frenulotomy on breastfeeding infants followed up for 3 months at Thammasat University Hospital. Pediatr Surg Int. 2016;32(10):945-52. 